\title{
Definition of Terms Used in Limitation of Treatment and Providing Palliative Care at the End of Life: The Indian Council of Medical Research Commission Report
}

\author{
Naveen Salins, Roop Gursahani', Roli Mathur' ${ }^{2}$, Shivakumar lyer ${ }^{3}$, Stanley Macaden ${ }^{4,5}$, Nagesh Simha ${ }^{6}$, Raj Kumar Mani ${ }^{7}$, M. R. Rajagopal ${ }^{8,9}$ \\ Department of Palliative Medicine, Tata Memorial Centre, ${ }^{1}$ Department of Neurology, P.D. Hinduja National Hospital, Mumbai, ${ }^{2}{ }^{2}$ CMR Bioethics Unit, National Centre

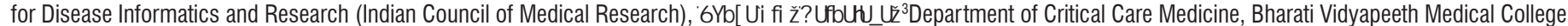 \\ 3XQ-IMMaharashtra, ${ }^{4}$ Palliative Care Program of the Christian Medical Association of India, ${ }^{5}$ Coordinator of the Palliative Care Program of Christian Medical Association of \\ India and Honorary Palliative Medicine Consultant at Bangalore Baptist Hospital, ${ }^{6}$ Medical Director, Karunashraya Hospice, Bengaluru, Karnataka, ${ }^{7} \mathrm{CEO}$ and Chairman, \\ Department of Critical Care, Pulmonology and Sleep Medicine, Nayati Medicity, Mathura, Uttar Pradesh, ${ }^{8}$ Chairman of Pallium India and Director of Trivandrum Institute \\ of Palliative Sciences, Pallium India, ${ }^{9}$ Trivandrum Institute of Palliative Sciences, Thiruvananthapuram, Kerala, India \\ (Republished with permission from the Indian Council of Medical Research)
}

\section{Abstract}

Background: Indian hospitals, in general, lack policies on the limitation of inappropriate life-sustaining interventions at the end of life. To facilitate discussion, preparation of guidelines and framing of laws, terminologies relating to the treatment limitation, and providing palliative care at the end-of-life care (EOLC) need to be defined and brought up to date. Methodology: This consensus document on terminologies and definitions of terminologies was prepared under the aegis of the Indian Council of Medical Research. The consensus statement was created using Nominal Group and Delphi Method. Results: Twenty-five definitions related to the limitations of treatment and providing palliative care at the end of life were created by reviewing existing international documents and suitably modifying it to the Indian sociocultural context by achieving national consensus. Twenty-five terminologies defined within the scope of this document are (1) terminal illness, (2) actively dying, (3) life-sustaining treatment, (4) potentially inappropriate treatment, (5) cardiopulmonary resuscitation (CPR), (6) do not attempt CPR, (7) withholding life-sustaining treatment, (8) withdrawing life-sustaining treatment, (9) euthanasia (10) active shortening of the dying process, (11) physician-assisted suicide, (12) palliative care, (13) EOLC, (14) palliative sedation, (15) double effect, (16) death, (17) best interests, (18) health-care decision-making capacity, (19) shared decision-making, (20) advance directives, (21) surrogates, (22) autonomy, (23) beneficence, (24) nonmaleficence, and (25) justice.

Keywords: End of life, limitation of treatment, palliative care

\section{Executive Summary}

This consensus document was prepared to standardize, update, and remove ambiguities in the definitions of terms relating to end-of-life care (EOLC). This is required to facilitate dialog, data collection, and research toward informing the development of bioethics and law relating to these areas.

\section{Definitions}

Terminal illness: An irreversible or incurable disease condition from which death is expected in the foreseeable future.

Actively dying: The hours or days preceding imminent death during which time the patient's physiological functions wane.

\begin{tabular}{|l|l|}
\hline \multicolumn{3}{c|}{ Access this article online } \\
\hline Quick Response Code: & Website: \\
& www.ijccm.org \\
& \\
&
\end{tabular}

Life-sustaining treatment: Life-sustaining treatment comprises any medical treatment that artificially supports or replaces a bodily function essential to the life of the person.

Address for correspondence: Dr. Raj Kumar Mani, Critical Care, Pulmonology and Sleep Medicine, Nayati Medicity, Mathura, Uttar Pradesh, India E-mail: raj.rkmjs@gmail.com Dr. M. R. Rajagopal, Pallium India,

Trivandrum Institute of Palliative Sciences, Thiruvananthapuram, Kerala, India. E-mail:mrraj47@gmail.com

This is an open access journal, and articles are distributed under the terms of the Creative Commons Attribution-NonCommercial-ShareAlike 4.0 License, which allows others to remix, tweak, and build upon the work non-commercially, as long as appropriate credit is given and the new creations are licensed under the identical terms.

For reprints contact: reprints@medknow.com

How to cite this article: Salins N, Gursahani R, Mathur R, Iyer S, Macaden S, Simha N, et al. Definition of terms used in limitation of treatment and providing palliative care at the end of life: The Indian Council of Medical Research Commission Report. Indian J Crit Care Med 2018;22:249-62. 
Potentially inappropriate treatment: It connotes interventions aimed at cure that carries far greater possibilities of harm than reasonable possibilities of benefit.

Cardiopulmonary resuscitation (CPR): It is an emergency medical procedure that combines chest compression often with artificial ventilation.

Do not attempt resuscitation: A decision not to initiate or perform CPR on the background of terminal illness in accordance with prior expressed wishes of the patient or surrogate.

Withholding of life-sustaining treatment: A decision made not to initiate or escalate a life-sustaining treatment in terminal illness in accordance with expressed wishes of the patient or surrogate.

Withdrawal of life-sustaining treatment: A decision made to cease or remove a life-sustaining intervention in terminal illness in accordance with expressed wishes of the patient or surrogate.

Euthanasia: Euthanasia is the intentional act of killing a terminally ill patient on voluntary request, by the direct intervention of a doctor for the purpose of the good of the patient.

Active shortening of life process: An active, intentional act to hasten death or shorten the life of a dying patient with terminal illness.

Physician-assisted suicide: An intentional act by the physician, on voluntary request of a dying patient with terminal illness, providing the means or methods with which to help a person to end his/her life.

Palliative care: Palliative care is a holistic approach to treatment that improves the quality of life of patients and their families facing the problems associated with life-threatening illness, through the prevention and relief of suffering.

EOLC: An approach to a terminally ill patient that shifts the focus of care to symptom control, comfort, dignity, quality of life, and quality of dying rather than treatments aimed at cure or prolongation of life.

Palliative sedation (PS): PS is the administration of sedative substances at the minimal dosages necessary intentionally to lower the consciousness level definitely or temporarily in a terminally ill patient.

Double effect: A principle that distinguishes the effects that are intended, from those that are unintended but may be adverse though foreseeable.

Death: Irreversible cessation of the heart and circulatory function or neurological function of the brain including the brainstem.

Best interests: A concept that requires physicians to ensure potential benefits to outweigh harms before undertaking medical interventions.
Health-care decision-making capacity: The capacity of a patient to make an independent, informed decision.

Shared decision-making: A dynamic process with responsibility for decisions about the medical care of a patient being shared between the health-care team and the patient or surrogates.

Advance directives: A statement made by a person with decision-making capacity stating his/her wishes regarding how to be treated or not treated at a stage when $\mathrm{s} /$ he loses such capacity.

Surrogate: Surrogate is a person or persons other than the health-care providers who is/are accepted as the representatives of the patient's best interests, who will make decisions on behalf of the patient when the patient loses decision-making capacity.

Autonomy: It is the right of an individual to make a free and informed decision.

Beneficence: A principle that makes it obligatory on the part of physicians to act in the best interests of patients.

Nonmaleficence: A principle that directs physicians to first of all not do harm.

Justice: In the context of medical care requires that all people be treated without prejudice and that health-care resources be used equitably.

\section{INTRODUCTION}

In the words of Lisa J Schultz, "If the push towards life sustaining technology were balanced with options for comfort care, more people would have the chance to transition to death with dignity and grace." Such a trend of pragmatism, driven by ethical considerations and humanistic values, has been palpably lacking in India. Indian hospitals, in general, lack policies on the limitation of inappropriate life-sustaining interventions at the end of life. In contrast in the USA and in Europe, such treatment limitations permit natural death in up to $90 \%$ of cases. ${ }^{[1,2]}$ Only a few centers in India report withdrawal of inappropriate life-sustaining interventions, where it preceded death in $22 \%-49 \%$ of deaths. ${ }^{[3-5]}$ Anticipatory directives and advance care planning are almost nonexistent, and patients are seldom referred to palliative care for symptom management and end-of-life care (EOLC) ${ }^{[6]}$ Family and caregivers of the deceased patients often feel that the patients at the end of life have poorly controlled symptoms and distress. ${ }^{[7]}$ Health-related communication is incompletely delivered as most hospitals do not have trained health-care providers equipped to provide EOLC. ${ }^{[8]}$ Patients are often burdened with impersonal and unwanted health technology at the end of life with humane and comforting touch usually lost in the bargain. ${ }^{[4]}$

The duty of the health-care provider is to mitigate suffering. ${ }^{[9]}$ It is "to cure sometimes, to relieve often, and to comfort always." $[10]$ There exists no exception to this principle, whether or not there is a medical consensus, when the disease is incurable and 
the death is imminent. Death is to be recognized as a natural culmination of life. ${ }^{[1]]}$ Care providers have the primary duty to improve quality of life all through life which includes the dying phase. In the latter situation, curative intent must give way to a focus on improving the quality of life of the patient. ${ }^{[12]}$ Indiscriminate and aggressive medical interventions in such situations violate the individual's right to live and die with dignity. ${ }^{[13]}$ Medical procedures must thus inevitably be limited, at a point judged by health-care providers, that continuation of treatment would cause considerable harm compared to benefits. Treatment limitation is an integral part of the shift of the goal of care from a cure-directed approach to palliative care and EOLC. ${ }^{[14]}$

EOLC is a person-centered, personalized perception of "good death," which encompasses all aspects of comprehensive care of an individual who is approaching his or her end of life. ${ }^{[15]}$ It is applicable to any person, any place, and any illness. It involves relief of physical, psychological, social, spiritual, and existential symptoms. ${ }^{[16]}$ It enables patients to die at the preferred place of choice and receive appropriate care by a trained health-care provider. It aims to provide universal access to standard palliative care at the end of life and believes that every individual should have a right to a good, peaceful, comfortable, and dignified death. ${ }^{[17]}$

There has been a considerable evolution of terminology pertaining to this area of healthcare over the past three decades. In India, the paradigm has remained rooted in curative treatment in all phases of life. The shift from cure to care has not been integrated into everyday practice. Quality of death as reflected in peace, dignity, and family presence at the time of death is seriously compromised when patients die in Intensive Care Units (ICUs) or hospitals as most prefer to die distress-free at home. Since this aspect of holistic healthcare is missing in our collective awareness, palliative care access in terms of infrastructure and expertise is limited. Understandably, corresponding evolution of bioethics has also been hampered. Consequently, bioethical concepts remain outdated and insufficient to resolve dilemmas continually generated by new developments in medicine. Moreover, the ethical principles governing the deployment and foregoing of life-support technologies have largely remained outside public and professional focus. One fundamental barrier to professional and public discourse on these issues in India is the lack of clarity on the spectrum of terms that are often mistaken for euthanasia. Although international consensus definitions exist in medical literature, they need to be interpreted and integrated into Indian health-care and cultural awareness. Therefore, the terminology pertaining to these fields has so far been alien to our common understanding. This scenario needs to be urgently addressed to bring our principles and practice up to date. This consensus document on terminology is prepared under the aegis of the Indian Council of Medical Research (ICMR) toward realizing this goal. It is of crucial importance to develop India-specific ethical and legal framework for end-of-life decision-making in clinical practice.
The following are the definitions of common terms used in EOLC and palliative care agreed upon by this expert group appointed by the ICMR. These are based on a review of existing international documents and national consensus on the matter.

\section{Methodology}

Using Nominal Group ${ }^{[18]}$ and Delphi method, ${ }^{[19]}$ the consensus statement on definition of terms used in limitation of treatment and providing palliative care at the end of life was created. Nominal group method was conducted on April 29, 2017, at Mathura, India, in which an expert group comprising critical-care physicians, palliative-care physicians, neurologists, physicians, ethicists, solicitors, and members from the lay public participated. The expert group discussed the contentious statements/items in the draft document until a consensus was achieved and a final set of draft definitions was created. After nominal group consensus meeting, a detailed draft of the definition of terms document emerged through a Delphi process. This draft document was placed in the ICMR website inviting expert and public comments. The comments received were incorporated, and document was revised and recirculated among the experts until the final consensus was achieved [Table 1].

\section{Explanatory Notes}

\section{Terminal illness}

According to the International Association of Hospice and Palliative Care, terminal illness is a progressive condition that has no cure and that can be reasonably expected to cause the death of a person within a foreseeable future. The definition is inclusive of both malignant and nonmalignant conditions and aging. A person has an eventually fatal condition if his/her death in the foreseeable future would not be a surprise. The terms eventually fatal or terminal condition are used interchangeably. In reference to the patient, language that refers to living with an eventually fatal or terminal condition is recommended. ${ }^{[21]}$

According to the American Cancer Society, it is an irreversible condition that in the near future will result in death or a state of permanent unconsciousness from which he/she is unlikely to recover. In most states, a terminal illness is defined as one in which the patient will die "shortly" whether or not the medical treatment is given. ${ }^{[43]}$

According to the Mosby's medical dictionary, terminal illness is an advanced stage of a disease with an unfavorable prognosis and no known cure.

Various authorities have quoted a specific duration of 6 or 12 months. However, there is no objective evidence to support timeframes. Therefore, this document does not provide any specific time frames.

\section{Actively dying}

Actively dying has not been well defined in the literature. It is normally described in terms of the last hours or days of life 


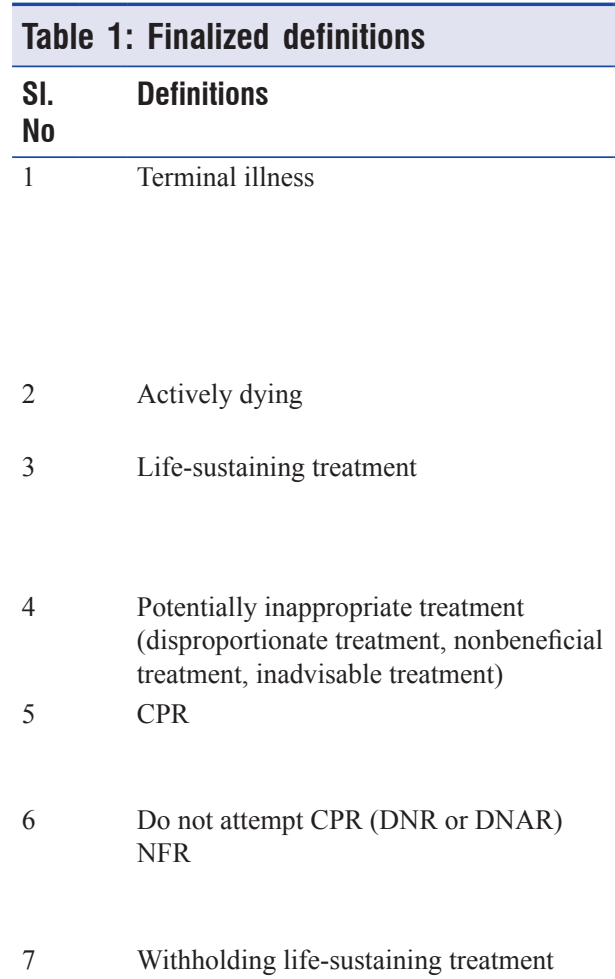

$8 \quad$ Withdrawing life-sustaining treatment

$9 \quad$ Euthanasia

11 Physician-assisted suicide

$12 \quad$ Palliative care

\section{Description}

Terminal illness is one from which recovery cannot be expected with the available treatment and death is considered to be unavoidable in the foreseeable future ${ }^{[20]}$

OR

An incurable and irreversible condition caused by injury, disease, or illness that would cause death within a reasonable period of time in accordance with accepted medical standards and where the application of life-sustaining treatment would serve only to prolong the process of dying ${ }^{[21]}$

The hours or days preceding imminent death during which time the patient's physiological functions wane ${ }^{[21]}$

Life-sustaining treatment comprises any medical treatment that artificially supports or replaces a body function essential to the life of the person. It includes CPR, endotracheal intubation, mechanical ventilation, vasopressor therapy, parenteral or artificial enteral nutrition, dialysis, blood products, antibiotics, and intravenous fluids ${ }^{[2]}$

It connotes interventions aimed at cure that carries greater possibilities of harm than reasonable possibilities of benefit. There is no general consensus about the use of the related term futility and use of this term should be avoided ${ }^{[23]}$

It is an emergency medical procedure that combines chest compression often with artificial ventilation in an effort to manually preserve intact brain function until further measures are taken to restore spontaneous blood circulation and breathing in a person who is in cardiac arrest ${ }^{[24]}$ A decision not to initiate or perform the CPR on the background of terminal illness where the patient's chances of surviving in the event that he/she needs CPR are extremely low and the patient fully aware of his/her terminal illness or if the patient is incompetent, a surrogate on behalf of the patient decides not to undergo $\mathrm{CPR}^{[25]}$

On a background of terminal illness, a decision made not to initiate or escalate a life-sustaining treatment, where the patient's chances of survival after initiation or escalation of life-sustaining treatment, is poor, with the burden outweighing the possible benefit, and the fully informed patient or if the patient is incompetent, a surrogate on behalf of the patient chooses not to initiate or escalate the life-sustaining treatment ${ }^{[26]}$

On a background of terminal illness, a decision made to cease or remove a life-sustaining intervention presently provided, where patient's chances of survival with continued life-sustaining treatment is poor with the burden outweighing the possible benefit and the fully informed patient or if the patient is incompetent, a surrogate on behalf of the patient chooses to cease the life-sustaining treatment ${ }^{[26]}$

Euthanasia is the intentional act of killing a dying patient with terminal illness by the direct intervention of a doctor, for the purpose of good of the patient. However, allowing natural death, withholding and withdrawing of life-sustaining treatment to limit harm, and suffering in a dying patient should not be construed as euthanasia ${ }^{[27]}$

The term passive euthanasia is an obsolete terminology and should be avoided as euthanasia cannot be passive and withholding or withdrawing a potentially inappropriate treatment in a patient dying with a terminal illness that only prolongs the dying process, cannot be construed as an intention to kill

An active act intended to hasten death or shorten the life of a dying patient with terminal illness. However, allowing natural death, withholding and withdrawing of life support to limit harm, and suffering in a dying patient should not be construed as active shortening of life $\mathrm{e}^{[2]}$

An intentional act by the physician, on voluntary request of a dying patient with terminal illness, providing the means or methods with an intention to help a person to end his/her life $\mathrm{f}^{[28]}$

According to the WHO, palliative care is an approach that improves the quality of life of patients and their families facing the problem associated with life-threatening illness, through the prevention and relief of suffering by means of early identification and impeccable assessment and treatment of pain and other problems, physical, psychosocial, and spiritual ${ }^{[29]}$

An approach to a terminally ill patient that shifts the focus of care to symptom control, comfort, dignity, quality of life, and quality of dying, rather than treatments aimed at cure or prolongation of life ${ }^{[30]}$

PS is the intentional administration of sedative substances at the minimal dosages necessary to lower the consciousness level definitely or temporarily of a person suffering from a terminal illness and having a short life expectancy (days to weeks) to obtain relief from one or several distressing symptoms refractory to standard treatment methods ${ }^{[31]}$

OR

Therapeutic (or palliative) sedation in the context of EOLC is the monitored use of appropriately titrated medications intended to induce a state of decreased or absent awareness (unconsciousness) to relieve the burden of otherwise intractable suffering due to distressing refractory symptoms in a manner that is ethically acceptable to the patient, family, and health-care providers ${ }^{[32]}$ 


\begin{tabular}{|c|c|c|}
\hline $\begin{array}{l}\text { SI. } \\
\text { No }\end{array}$ & Definitions & Description \\
\hline 15 & Double effect & $\begin{array}{l}\text { This principle distinguishes the effects that are intended, from those that are foreseeable though } \\
\text { unintended. The principle justifies the appropriate use of palliative analgesia and sedation, specifically } \\
\text { to relieve suffering, even at the remote risk of hastening death as a side effect, which is unintended }{ }^{[33]}\end{array}$ \\
\hline \multirow[t]{3}{*}{16} & Death & $\begin{array}{l}\text { Irreversible cessation of the heart and circulatory function or neurological function of the brain } \\
\text { including brainstem }\end{array}$ \\
\hline & & OR \\
\hline & & $\begin{array}{l}\text { "Deceased person" means a person in whom permanent disappearance of all evidence of life } \\
\text { occurs, by reason of brainstem death or in a cardiopulmonary sense, at any time after live birth } \\
\text { has taken place }{ }^{[35]}\end{array}$ \\
\hline 17 & Best interests & $\begin{array}{l}\text { The best interest concept holds that the physicians and other health-care providers must weigh } \\
\text { the benefits and risks of treatments and select ones in which the benefits are maximized and the } \\
\text { risks minimized for the patient. This is not based on value judgments but on objective criteria } \\
\text { prescribed by professional and societal standards }{ }^{[36]}\end{array}$ \\
\hline 18 & Health-care decision-making capacity & $\begin{array}{l}\text { Health-care decision-making capacity is the capacity of an individual to make an informed } \\
\text { decision after fully understanding the nature of intervention, purpose of intervention, risks and } \\
\text { benefits of intervention, risks of not carrying out the intervention, and risks and benefits of } \\
\text { alternate interventions }{ }^{[36]}\end{array}$ \\
\hline 19 & Shared decision-making & $\begin{array}{l}\text { A dynamic process with responsibility for decisions about the medical care of a patient being } \\
\text { shared between the health-care team and the patient or the patient's surrogates }{ }^{[37]}\end{array}$ \\
\hline 20 & Advance directives & $\begin{array}{l}\text { A statement made by a person with the decision-making capacity stating his/her wishes regarding } \\
\text { how to be treated or not treated at a stage when s/he loses such capacity. Advance directives include } \\
\text { living wills or health-care proxies and become operational only after the person loses capacity }{ }^{[38]}\end{array}$ \\
\hline 21 & Surrogate & $\begin{array}{l}\text { Surrogate is a person or persons other than the health-care providers who is/are accepted as the } \\
\text { representatives of the patient's best interests, who will make decisions on behalf of the patient } \\
\text { when the patient loses his/her capacity to make health-care decisions. It has to be a designated/ } \\
\text { nominated person by the patient, who may or may not be a family member. In the absence of } \\
\text { such designation or nomination, the next of kin of the patient will be considered as surrogates }{ }^{[38]}\end{array}$ \\
\hline \multirow[t]{2}{*}{22} & Autonomy & $\begin{array}{l}\text { Autonomy is the right of an individual to make a free and informed decision. Autonomy, in the } \\
\text { context of medical practice, includes the patient's right to full information and to participate in } \\
\text { medical decision-making. This includes the right to refuse interventions }{ }^{[39]}\end{array}$ \\
\hline & & $\begin{array}{l}\text { The person's right to autonomously voice their end-of-life treatment choices has to be respected, } \\
\text { considering the use of advance treatments and their prognosis. This right of autonomy has some } \\
\text { limitations and hence may face an ethical dilemma. Ethics require that patients do not receive } \\
\text { EOLC which is inconsistent with their EOLC preferences }\end{array}$ \\
\hline \multirow[t]{2}{*}{23} & Beneficence & This principle makes it obligatory on the part of physicians to act in the best interests of patients ${ }^{[0]]}$ \\
\hline & & $\begin{array}{l}\text { Physicians have to judge the EOLC situation and provide appropriate treatment prognosis so that } \\
\text { patients can make an autonomous choice of treatment preferences or patients' family can make } \\
\text { these choices for them and work toward act of beneficence for the patient. While carrying out } \\
\text { this act of beneficence, the physician has to provide information about the treatment, especially } \\
\text { in case of futile treatments so as to avoid any undue harm to the patient. The health-care services } \\
\text { should not only target lengthening the life of patients but also improve their quality of life }\end{array}$ \\
\hline 24 & Nonmaleficence & $\begin{array}{l}\text { This principle directs physicians to first of all not do harm. The harm also includes harm to } \\
\text { patients' whole-person interests, expressed as values and wishes }{ }^{[41]}\end{array}$ \\
\hline \multirow[t]{2}{*}{25} & Justice & $\begin{array}{l}\text { In the context of medical care requires that all people be treated without prejudice and } \\
\text { health-care resources be used equitably }{ }^{[42]}\end{array}$ \\
\hline & & $\begin{array}{l}\text { Rationing of care is present in the current health-care system in most countries and can be } \\
\text { justified if carried out ethically and equitably. There is a need for evaluating and assessing } \\
\text { the medically advanced treatment so as to avoid any undue use of already limited resources. } \\
\text { Considering the aspect of access of quality care to the people who need them most, rationing of } \\
\text { care in futile situations is often justified }\end{array}$ \\
\hline
\end{tabular}

EOLC: End-of-life care; DNR: Do not resuscitate; DNAR: Do not attempt cardiopulmonary resuscitation; CPR: Cardiopulmonary resuscitation; NFR: Not for resuscitation; WHO: World Health Organization; PS: Palliative sedation

and presence of unique signs and symptoms preceding death. There is a paucity of literature on the signs of impending death. Further studies are needed to examine specific signs that may signal that the patient is actively dying and to allow clinicians to educate family members and make appropriate recommendations toward maximizing comfort and minimizing aggressive measures. ${ }^{[21]}$

\section{Life-sustaining treatment}

According to the British Medical Association, this refers to all treatments which has the potential to postpone the patient's death and includes cardiopulmonary resuscitation (CPR), artificial ventilation, blood products, pacemakers, left ventricular-assisted devices, vasopressors, specialized treatments for particular conditions, such as chemotherapy or 
dialysis, antibiotics when given for a potentially life-threatening infection, and artificial nutrition and hydration. ${ }^{[44]}$

\section{Potentially inappropriate treatment}

According to the official policy statement of the American Thoracic Society, the American Association for Critical Care Nurses, the American College of Chest Physicians, the European Society for Intensive Care Medicine, and the Society of Critical Care Medicine, the term "potentially inappropriate" should be used, rather than "futile," to describe treatments that have at least some chance of accomplishing the effect sought by the patient. Clinicians should communicate and advocate for the treatment plan that they believe is appropriate. Requests for potentially inappropriate treatments that remain intractable despite intensive communication and negotiation should be managed by a fair process of conflict resolution. ${ }^{[45]}$

\section{Justification}

The committee recommends the use of the term "potentially inappropriate" rather than "futile" to emphasize two important aspects of such judgments. First, the word "inappropriate" conveys more clearly than the word "futile" or "ineffective" that the assertion being made by clinicians depends on both technical medical expertise and a value-laden claim, rather than strictly a technical judgment. Second, the word "potentially" signals that the judgments are preliminary, rather than final, and require review before being acted on. The ethical concerns that may be raised to justify the refusals include concerns that the treatment is highly unlikely to be successful, is extremely expensive, or is intended to achieve a goal of controversial value.

\section{Cardiopulmonary resuscitation}

According to the International Liaison Committee on Resuscitation, Cardiopulmonary resuscitation, commonly known as CPR, is an emergency procedure that combines chest compression often with artificial ventilation in an effort to manually preserve intact brain function until further measures are taken to restore spontaneous blood circulation and breathing in a person who is in cardiac arrest. It is indicated in those who are unresponsive with no breathing or abnormal breathing, for example, agonal respirations. ${ }^{[24]}$

\section{Do not attempt resuscitation}

According to the American Heart Association guidelines, a do not attempt resuscitation (DNAR) order is given by a licensed physician or alternative authority as per local regulation, and it must be signed and dated to be valid. In many settings, "allow natural death" is becoming a preferred term to replace DNAR, to emphasize that the order is to allow natural consequences of a disease or injury, and to emphasize ongoing EOLC. The DNAR order should explicitly describe the resuscitation interventions not to be performed in the event of a life-threatening emergency. In most cases, a DNAR order is preceded by a documented discussion with the patient, family, or surrogate decision-maker addressing the patient's wishes about resuscitation interventions. In addition, some jurisdictions may require confirmation by a witness or a second treating physician. ${ }^{[46]}$

\section{Withholding life-sustaining treatment}

According to the Guardianship and Administration Act 2000 and the Powers of Attorney Act 1998 in the US, it is the decision to withhold medical treatment prospectively: That is, whether or not to commence treatment for event/s yet to take place. This may involve a dimension of uncertainty because there could be unknowns about the future clinical state of the patient, for example, when and if the patient will suffer a cardiac arrest, necessitating CPR. ${ }^{[47]}$

\section{Withdrawing life-sustaining treatment}

According to the Guardianship and Administration Act 2000 and the Powers of Attorney Act 1998 in the US, the decision to withdraw a life-sustaining measure implies that a level of acceptance about the benefits of continuing the measures has been reached, both by the clinicians involved and the family. The decision signifies that a stage has been reached where the evidence points to the fact that the patient undeniably and irrefutably is receiving no benefit from the interventions proposing to be withdrawn. Arguably, the consent processes for withdrawing medical treatment may be less onerous than for withholding medical treatment, most likely because the patient's condition has stabilized to the extent that no further improvement is expected. ${ }^{[47]}$ The worldwide consensus is that both withdrawal and withholding are ethically acceptable in the context of EOLC, are similar, and are to be considered together. ${ }^{[48]}$ They both flow from the same principle of reducing unwanted harms to a terminally ill patient. Physicians and family may experience more distress and dilemma with the withdrawal decision. Both are based on the premise that the dying process is attributable to the disease afflicting the patient and not to the acts of withholding or withdrawal as they both belong to the principle of "omitting to struggle" when harms outweigh benefits. In both cases, the treatment shifts to comfort care in meticulous detail. ${ }^{[49]}$ If withdrawal were to be avoided at all costs, then the opportunity of a trial of curative interventions could be lost to some patients.

\section{Euthanasia}

Euthanasia is defined as direct intentional killing of a person as part of the medical care being offered. The withholding or withdrawing of artificial life-support procedures for a terminally ill patient is not euthanasia. Withholding/withdrawing life-sustaining treatment, taking into account the patient's benefits, wishes of the patient and family, and when based upon the principle of the potential inappropriateness of treatment for a terminal patient, is legally acceptable and appropriate. ${ }^{[27]}$

\section{Passive euthanasia}

Although the term passive euthanasia is used by some people to mean withholding or withdrawing life-sustaining treatment, the term is not used in medically advanced countries when the subject is officially discussed. Notable examples include 
deciding to Forego Life-Sustaining Treatment (a report on the ethical, medical, and legal issues in treatment decisions) published by the Presidents Commission for the Study of Ethical Problems in Medicine and Biomedical and Behavioral Research of USA, 1983, and the Report of the House of Lords Select Committee on Medical Ethics of UK, 1994. The term is also not used in the professional guidelines on the subject in various medically advanced countries. ${ }^{[50]}$

Withholding or withdrawing life-sustaining treatment, if done under appropriate circumstances, is ethically and legally acceptable. This is ethically and legally different from euthanasia as the latter is direct intentional killing of a person as part of the medical care being offered. To use the term passive euthanasia to describe the appropriate withholding or withdrawal of life-sustaining treatment may give people the wrong impression that such a decision is ethically and legally similar to active euthanasia. Withholding or withdrawing life-sustaining treatment includes widely different situations, ranging from withholding CPR in a terminally ill malignancy patient to withdrawing artificial nutrition in a patient in persistent vegetative state (PVS). The former is noncontroversial, but the latter can be controversial. If the term passive euthanasia is used, people may relate all discussions around withholding or withdrawing life-sustaining treatment to the controversial situations like the latter. ${ }^{[51]}$

The term passive euthanasia may contain the meaning of an intention to kill. We support withholding or withdrawing futile treatment which only prolongs the dying process, but we do not support an intention to kill. Avoiding the misleading term passive euthanasia but using the more neutral term withholding or withdrawing life-sustaining treatment would thus facilitate public discussion on the topic. This would also facilitate discussion with the patients and families in individual cases when such discussion is required. ${ }^{[52]}$

\section{Active shortening of life}

According to the ethics in European ICUs study, active shortening of the dying process was defined as a circumstance in which someone performed an act with the specific intent of shortening the dying process; these acts did not include withholding or withdrawing treatment although withholding or withdrawing could occur before shortening of dying process. Examples included an intentional overdose of narcotics, anesthetics, or potassium chloride. ${ }^{[2]}$

The term "shortening of the dying process" was used instead of active euthanasia because Dutch investigators insisted that the term "active euthanasia" could not include most ICU patients who could not request the action. Several other terms were considered, but shortening of the dying process was accepted by all investigators as it describes the intent and the action that occurs and is a more neutral term that physicians might more readily record. In addition, as some investigators might still be reluctant to admit to shortening of the dying process, another question was added to evaluate the highest possible incidence of actions that might be considered active euthanasia (although most of these actions were probably not active euthanasia). For each patient, physicians were asked whether any other action (not forgoing therapy) taken to relieve patient suffering may have contributed to the patient's death. ${ }^{[53]}$

\section{Physician-assisted suicide}

According to the Hastings Center Bioethics Briefing, physician-assisted suicide refers to the practice where a physician provides a potentially lethal medication to a terminally ill, suffering patient at his/her request that he/she can take (or not) at a time of his/her own choosing to end his/her life. It is also called physician-assisted suicide, physician aid-in-dying, and patient-administered hastened death. ${ }^{[54]}$

\section{Palliative care}

According to the $\mathrm{WHO}$, palliative care is an approach that improves the quality of life of patients and their families facing the problem associated with life-threatening illness, through prevention and relief of suffering by means of early identification and impeccable assessment and treatment of pain and other problems, physical, psychosocial, and spiritual. ${ }^{[29]}$

\section{Palliative care:}

1. Provides relief from pain and other distressing symptoms

2. Affirms life and regards dying as a normal process

3. Intends neither to hasten nor to postpone death

4. Integrates the psychological and spiritual aspects of patient care

5. Offers a support system to help patients live as actively as possible until death

6. Offers a support system to help the family cope during the patient's illness and in their own bereavement

7. Uses a team approach to address the needs of patients and their families, including bereavement counseling, if indicated

8. Will enhance quality of life and may also positively influence the course of illness

9. Is applicable early in the course of illness, in conjunction with other therapies that are intended to prolong life such as chemotherapy or radiation therapy, and includes those investigations needed to better understand and manage distressing clinical complications. ${ }^{[29]}$

\section{End-of-life care}

According to the General Medical Council UK, patients are "approaching the end of life" when they are likely to die within the next 12 months. This includes those patients whose death is expected within hours or days; those who have advanced, progressive incurable conditions; those with general frailty and coexisting conditions that mean they are expected to die within 12 months; those at risk of dying from a sudden acute crisis in an existing condition; and those with life-threatening acute conditions caused by sudden catastrophic events. The term "approaching the end of life" can also apply to extremely premature neonates whose prospects for survival are known to be very poor and patients who are diagnosed as being in a PVS for whom a decision to withdraw treatment and care may lead to their death. ${ }^{[55-57]}$ 
Palliative care encompasses EOLC. Therefore, these terms are being increasingly used together as they both are essential components for the holistic care at the end of life. Guidelines on EOLC tell us that palliative care starts side by side with curative intent and carries on as an increasing component becoming the mainstay of treatment in EOLC. Treatment limitation does not indicate abandonment of patient but shift in the focus of care from cure to comfort and improvement in quality of life. ${ }^{[58]}$

\section{Palliative sedation}

According to the position statement of American Association of Hospice Palliative Medicine, palliative sedation (PS), as defined in this statement, is the intentional lowering of awareness toward, and including, unconsciousness for patients with severe and refractory symptoms. ${ }^{[59]}$

PS must satisfy the criteria of having a specific clinical indication, a target outcome, and a benefit/risk ratio that is acceptable to both the clinician and the patient or patient's surrogates. PS is an intervention reserved for extreme situations. The use of PS should only be considered after all available expertise to manage the target symptom has been accessed. The level of sedation should be proportional to the patient's level of distress. As with all treatments, patients, when able, should participate in the decision to use PS. Treatment of other symptoms should be continued alongside PS because sedation may decrease the patient's ability to communicate or display discomfort. ${ }^{[31]}$

PS raises ethical concerns when it significantly reduces patient consciousness to the degree that the patient is unable to substantially interact with others, does not have the ability or opportunity to change his mind, and is unable to eat and drink (thus potentially shortening survival in particular circumstances). PS is ethically defensible (1) when used after careful interdisciplinary evaluation and treatment of the patient, (2) when palliative treatments that are not intended to affect consciousness have failed or, in the judgment of the clinician, are very likely to fail, (3) where its use is not expected to shorten the patient's time to death, and (4) only for the actual or expected duration of symptoms. PS should not be considered irreversible in all circumstances. It may be appropriate, in some clinical situations when symptoms are deemed temporary, to decrease sedation after a predetermined time to assess efficacy, continued symptoms, and need for ongoing sedation. ${ }^{[32]}$

In clinical practice, PS usually does not alter the timing or mechanism of a patient's death as refractory symptoms are most often associated with very advanced terminal illness. Practitioners who use PS should be clear in their intent are to palliate the symptoms and not to shorten survival. Because patients receiving PS are typically close to death, most patients will no longer have desire to eat or drink. Artificial nutrition and hydration are not generally expected to benefit the patient receiving PS. However, questions about the use of artificial nutrition and hydration should be addressed before PS is undertaken. ${ }^{[60]}$
Sedation is used in palliative care in several settings: (1) transient sedation for noxious procedures; (2) sedation as part of burn care; (3) sedation used in end of life weaning from ventilator support; (4) sedation in the management of refractory symptoms at the end of life; (5) emergency sedation; (6) respite sedation; and (7) sedation for psychological or existential suffering. However, sedation for psychological and existential suffering needs greater exposition and consensus before it is considered as grounds for practice of PS in the Indian setting.

\section{Double effect}

The essence of the doctrine of double effect is that an act performed with good intent can still be moral despite unforeseen unintended effects. In the context of EOLC, this can arise when four conditions are met: ${ }^{[33]}$

1. Administering strong analgesics for relief of severe pain is not, in itself, immoral

2. The intention is to relieve severe pain and not to hasten the patient's death

3. The relief of severe pain is not achieved through causing the patient's death

4. Proportionally, the need to relieve severe pain is such that it warrants accepting a remote possibility of shortening of life.

\section{Death}

According to the Academy of Medical Royal Colleges, death is defined as the simultaneous and irreversible onset of apnea and unconsciousness in the absence of the circulation. ${ }^{[61]}$ Full and extensive attempts at reversal of any of the contributing cause to the cardiorespiratory arrest have been made. Such factors include body temperature and endocrine, metabolic, and biochemical abnormalities.

Moreover, death could also ensue due to an individual meeting the criteria for not attempting CPR, or attempts at CPR have failed, or treatment aimed at sustaining life has been withdrawn because it has no further benefit to the patient and not in his/her best interest to continue or not consistent with patient's wishes communicated via an advanced directive to refuse treatment

The individual should be observed by the person responsible for confirming death for a minimum of $5 \mathrm{~min}$ to establish that irreversible cardiorespiratory arrest has occurred. The absence of mechanical cardiac function is normally confirmed using a combination of the following: absence of a central pulse on palpation and the absence of heart sounds on auscultation. These criteria will normally suffice in the primary-care setting. However, their use can be supplemented in the hospital setting by one or more of the following: asystole on a continuous electrocardiographic (ECG) display, absence of pulsatile flow using direct intra-arterial pressure monitoring, or absence of contractile activity using ECG.

Any spontaneous return of cardiac or respiratory activity during this period of observation should prompt a further 5-min observation from the next point of cardiorespiratory arrest. 
After 5 min of continued cardiorespiratory arrest, the absence of the pupillary responses to light, of the corneal reflexes, and of any motor response to supra-orbital pressure should be confirmed. The time of death is recorded as the time at which these criteria are fulfilled.

\section{Best interests}

According to the Mental Capacity Act 2005 UK, the act sets out what health-care provider must consider when deciding what is in the best interests of your patient. Health-care provider should take into account: past and present wishes and feelings, beliefs, and values that may have influenced the decision being made, and what other factors that the patient would be likely to consider if they had capacity. ${ }^{[36]}$

Health-care providers must have objective reasons for any decisions made. They must also be able to show that they have considered all the circumstances relevant to the decision in question. In trying to assess the best interests of a person lacking capacity, the health-care provider should encourage the person lacking capacity to participate in the decision. To do this, it may be necessary to use specific communication methods; for example, simple language or pictures or using a specialist to help communicate.

1. Avoid discrimination: The Act specifically states that decisions cannot be based on a person's age, appearance, or condition or any aspect of the person's behavior. The appearance can refer to all aspects of a person's physical appearance, while the condition can include learning difficulties, age-related illnesses, or temporary conditions (such as unconsciousness or drunkenness)

2. Health-care provider should identify all the issues most relevant to the person who lacks capacity and to the specific decisions to be made. These will vary from case to case, depending on the capacity of the patient and the decision needing to be made. If possible, it is advised to defer the decision until the patient is likely to regain the capacity. However, in emergency situations, it may not be possible to wait for the patient to regain capacity. ${ }^{[62]}$

\section{Health-care decision-making capacity}

According to the General Medical Council UK, health-care provider must assess patient's capacity to make a particular decision at the time it needs to be made.

Health-care providers must not assume that because a patient lacks capacity to make a decision on a particular occasion, they lack capacity to make any decisions at all or will not be able to make similar decisions in the future.

They must take account of the advice on assessing capacity in the Codes of Practice that accompany the Mental Capacity Act 2005, the Adults with Incapacity (Scotland) Act 2000, and other relevant guidance. If the assessment is that the patient's capacity is borderline, then the health-care provider must be able to show that it is more likely than not that they lack capacity. ${ }^{[63]}$

If the assessment leaves the health-care provider in doubt about the patient's capacity to make a decision, then they should seek advice from:

1. Nursing staff or others involved in the patient's care, or those close to the patient, who may be aware of the patient's usual ability to make decisions and their particular communication needs

2. Colleagues with relevant specialist experience, such as psychiatrists, neurologists, or speech and language therapists. If they are still unsure about the patient's capacity to make a decision, they must seek legal advice with a view to asking a court to determine capacity.

In making decisions about the treatment and care of patients who lack capacity, they must:

1. Make the care of the patient as their first concern

2. Treat patients as individuals and respect their dignity

3. Support and encourage patients to be involved, as far as they want to and are able, in decisions about their treatment and care

4. Treat patients with respect and not discriminate against them.

They must also consider:

1. Whether the patient's lack of capacity is temporary or permanent

2. Which options for treatment would provide overall clinical benefit for the patient

3. Which option, including the option not to treat, would be least restrictive of the patient's future choices

4. Any evidence of the patient's previously expressed preferences, such as an advance statement or decision

5. The views of anyone the patient asks you to consult or who has legal authority to make a decision on their behalf or has been appointed to represent them

6. The views of people close to the patient on the patient's preferences, feelings, beliefs, and values and whether they consider the proposed treatment to be in the patient's best interests

7. What they and the rest of the health-care team know about the patient's wishes, feelings, beliefs, and values. ${ }^{[64]}$

\section{Shared decision-making}

According to General Medical Council UK, the exchange of information between doctor and patient is central-to-good decision-making. ${ }^{[65]}$ How much information the health-care providers share with patients will vary, depending on their individual circumstances. They should tailor their approach regarding discussions with patients according to:

1. Patient's needs, wishes, and priorities

2. Patient's level of knowledge about, and understanding of, their condition, prognosis, and treatment options

3. The nature of patient's condition

4. The complexity of the treatment

5. The nature and level of risk associated with the investigation or treatment.

Health-care provider should not make assumptions about:

1. The information a patient might want or need

2. The clinical or other factors a patient might consider 
significant

3. A patient's level of knowledge or understanding of what is proposed.

Health-care provider must give patients the information they want or need about:

1. The diagnosis and prognosis

2. Any uncertainties about the diagnosis or prognosis, including options for further investigations

3. Options for treating or managing the condition, including the option not to treat

4. The purpose of any proposed investigation or treatment and what it will involve

5. The potential benefits, risks, and burdens and the likelihood of success for each option; this should include information, if available, about whether the benefits or risks are affected by which organization or doctor is chosen to provide care

6. Whether a proposed investigation or treatment is part of a research program or is an innovative treatment designed specifically for their benefit

7. The people who will be mainly responsible for and involved in their care, what their roles are, and to what extent students may be involved

8. Their right to refuse to take part in teaching or research

9. Their right to seek a second opinion

10. Any bills they will have to pay

11. Any conflicts of interest with the provider and provider's organization, with regard to any treatments that the providers believe to have a greater potential benefit for the patient than those that the provider's organization can offer.

Health-care provider should explore these matters with the patients, listen to their concerns, ask for and respect their views, and encourage them to ask questions.

Health-care providers should check whether the patients have understood the information they have been given and whether or not they would like more information before making a decision. They must make it clear that they can change their mind about a decision at any time. They must answer patients' questions honestly and as far as possible practical and fully. ${ }^{[6]}$

\section{Advance directives}

According to the National Hospice and Palliative Care Organization, advance care planning is making decisions about the care the patients would like to receive if they become unable to speak for themselves. These are the decisions the patients should make, regardless of what they choose for their future care, and the decisions that are based on patient's personal values, preferences, and discussions with their loved ones. Advance care planning includes:

1. Getting information on the types of life-sustaining treatments that are available

2. Deciding what types of treatment, patients would or would not want should they be diagnosed with a life-limiting illness
3. Sharing their personal values with their loved ones

4. Completing advance directives to put into writing what types of treatment they would or would not want should they be unable to speak for themselves.

Decisions about EOLC are deeply personal and are based on patient's values and beliefs. Because it is impossible to foresee every type of circumstance or illness, it is essential to think, in general, about what is important to them. Conversations that focus on patient's wishes and beliefs will relieve the loved ones and health-care providers of the need to guess what they would want. ${ }^{[67]}$

\section{Surrogate}

According to the Illinois Health Care Surrogate Act, "surrogate decision-maker" means an adult individual or individuals who:

1. Have decisional capacity

2. Are available upon reasonable inquiry

3. Are willing to make medical treatment decisions on behalf of a patient who lacks decisional capacity

4. Are identified by the attending physician in accordance with the provisions of this Act as the person or persons who is or are to make those decisions in accordance with the provisions of this Act. ${ }^{[68]}$

The Act goes on to make the following clarifications:

a. When a patient lacks decisional capacity, the health-care provider must make a reasonable inquiry as to the availability and authority of a health-care agent under the Powers of Attorney for Health Care Law. When no health-care agent is authorized and available, the health-care provider must make a reasonable inquiry as to the availability of possible surrogates. A reasonable inquiry includes, but is not limited to, identifying a member of the patient's family or other health-care agent by examining the patient's personal effects or medical records. The surrogate decision-makers, as identified by the attending physician, are then authorized to make decisions as follows: (1) for patients who lack decisional capacity and do not have a qualifying condition, medical treatment decisions may be made according to a shared decision-making model; (2) for patients who lack decisional capacity and have a qualifying condition, medical treatment decisions including whether to forgo life-sustaining treatment on behalf of the patient may be made without court order or judicial involvement. In the absence of designated or nominated surrogate decision-makers, the next of kin is considered to be a surrogate. According to the Organ Transplant Act of India, ${ }^{[69]}$ first relatives (spouse, parents, children, grandparents, brothers, and sisters) are considered as next of kin

The health-care provider shall have the right to rely on any of the above surrogates if the provider believes after reasonable inquiry that neither a health-care agent under the Powers of Attorney for Health Care Law nor a surrogate of higher priority is available 
Where there are multiple surrogate decision-makers at the same priority level in the hierarchy, it shall be the responsibility of those surrogates to make reasonable efforts to reach a consensus as to their decision on behalf of the patient regarding the forgoing of life-sustaining treatment. If two or more surrogates who are in the same category and have equal priority, they indicate to the attending physician that they disagree about the health-care matter at issuel; a majority of the available persons in that category (or the parent with custodial rights) shall control, unless the minority (or the parent without custodial rights) initiates guardianship proceedings in accordance with the Probate Act of 1975. No health-care provider or other person is required to seek appointment of a guardian ${ }^{[70]}$

b. After a surrogate has been identified, the name, address, telephone number, and relationship of that person to the patient shall be recorded in the patient's medical record

c. Any surrogate who becomes unavailable for any reason may be replaced by applying the provisions of Section 25 in the same manner as for the initial choice of surrogate

d. In the event an individual of a higher priority to an identified surrogate becomes available and willing to be the surrogate, the individual with higher priority may be identified as the surrogate. In the event an individual in a higher-, a lower-, or the same priority-level or a health-care provider seeks to challenge the priority of or the life-sustaining treatment decision of the recognized surrogate decision-maker, the challenging party may initiate guardianship proceedings in accordance with the Probate Act of 1975

e. The surrogate decision-maker shall have the same right as the patient to receive medical information and medical records and to consent to disclosure

f. Any surrogate shall have the authority to make decisions for the patient until removed by the patient who no longer lacks decisional capacity, appointment of a guardian of the person, or the patient's death.

\section{Autonomy}

According to Beauchamp and Childress, Principles of Biomedical Ethics, autonomy is respecting the decision-making capacities of autonomous persons; enabling individuals to make reasoned, informed choices. This translates into practice as the right of informed consent or refusal..$^{[71]}$ It is the respect for the right of a mentally competent individual to consent or to refuse clinically indicated medical treatment (including life-sustaining treatment). The choice should be based on adequate information, and the individual takes responsibility for such choice. For any medical intervention, except in special circumstances, a consent form needs to be signed by the patient or surrogate. Physicians are by common law bound to respect patient's refusal who has received complete information even if this would lead to his or her death. Respect for patient's autonomy is sometimes extended to include respect for patient's bodily integrity. For example, for mentally incompetent individuals who cannot express preferences and make a choice, decisions on life-sustaining treatment should nonetheless take into account their bodily integrity. ${ }^{[72]}$ The physician's approach should be to address the patient as a whole person than merely as a disease entity. Open and complete disclosure of information is thus an essential part of empowering the patient in taking an autonomous decision. To be able to exercise his/her autonomy directly, the patient should be mentally competent to identify and express his/her choices. If the patient has lost capacity, the right of autonomy is maintained through other means. His/her preferences are to be elicited from the next of kin or a duly-appointed legal representative and are termed as "substituted judgment." ${ }^{\text {[73] }} \mathrm{An}$ Advance Will is an instrument for the expression of autonomy in anticipation of one's loss of capacity. When the patient's values and wishes are known, they are integrated into the end-of-life decision-making. ${ }^{[7]}$ The right to privacy judgment in India (Justice Puttaswamy vs. The Union of India, 2017) adds immense weight to the principle of autonomy even without an Act specific to self-determination. It states that the right to privacy should be regarded as an unalienable fundamental right on its own, not as an extension of right to life. This is fundamental to restoring the right of the patient to choose the manner of his/her treatment when facing terminal illness. The right to privacy would be violated if this principle is not followed in practice. This right must be seen to be respected even when the patient is incompetent and would operate through a mechanism: either an instructive directive such as advance will or an authorized power of attorney appointed by the patient; in the absence of these the natural surrogates such as the next of kin. The Mental Healthcare Act 2017 further supports the principle of autonomy pertaining to healthcare and the right to use an instrument such as Advance Will.

\section{Beneficence}

According to Beauchamp and Childress, Principles of Biomedical Ethics, this considers the balancing of benefits of treatment against the risks and costs; the health-care professional should act in a way that benefits the patient. It also includes duty of care and due regard for patient's welfare and interests (to preserve life, relieve suffering, and limit disability). Related professional terms and concepts include patient's best interests and patient's benefit. ${ }^{[72]}$ Beneficence flows from the fiduciary obligation to act always in patient's best interests. In terminal illness, since benefits of a curative intervention are negligible, foregoing of life support would be in patient's best interests. ${ }^{[71]}$ This is even more so when patients' values and preferences suggest that such interventions are unwanted. Best interests also include protecting him/her and the family from economic or social difficulties when these are clearly expressed. ${ }^{[75]}$ Physician's insisting on continuation of futile therapies is therefore regarded as a violation of this principle.

\section{Nonmaleficence}

According to Beauchamp and Childress, Principles of Biomedical Ethics, it involves avoiding the causation of harm; the health-care 
professional should not harm the patient. All treatment involves some harm, even if minimal, but the harm should not be disproportionate to the benefits of treatment. In the context of EOLC, non maleficence implies avoiding prolonging suffering by employing potentially inappropriate medical interventions, and to adequately consider the risks and harms of interventions. ${ }^{[72]}$ Harm confined only to the physiological standpoint would be too narrow and interpretation. A dying patient and family should be given the opportunity to prepare for death. ${ }^{[74]}$

An appropriate environment for ensuring good death should be made available. All the while, whole-person interests should be safeguarded. The family too must be protected from harm that may accrue from incomplete information, financial pressure of disproportionate treatments and posttraumatic stress disorder from inadequate attention to counseling during the dying process and bereavement.

Freedom from pain and distress is a fundamental right, and withholding adequate palliative therapy would violate this principle. The doctrine of "double effect" addresses the situation when adequate analgesia and sedation may have the unintended side effect of shortening the dying process. ${ }^{[76]}$ This principle clearly sets the obligation to provide freedom from pain and distress above the principle "to do no harm provided, the harm is unintended." "[77] Intention is revealed in the care taken to titrate the drug dosing which would mean that protocols for palliative therapy should be in place and documentation should be meticulous. ${ }^{[78]}$ However, doses beyond usual recommendations should be adequately justified.

\section{Justice}

According to Beauchamp and Childress, Principles of Biomedical Ethics, it involves distributing benefits, risks, and costs fairly; the notion that patients in similar positions should be treated in a similar manner. Treating all persons according to what is fair or due to them. A related concept often considered is equity. An individual should not be unfairly treated (discriminated) based on disability, age, social status, etc. On the other hand, an individual cannot claim unlimited right (e.g., to be treated at all costs), without regard to the impact on other persons or to the scarcity of resources. ${ }^{[72,79]}$ In other words, social justice means allocating resources appropriate to the medical condition of the patient to maximize their benefits and minimize wastage. Futile application of therapies would clearly violate this social obligation. Situations may arise when patient or family may insist on therapies physicians would consider inappropriate, when the principles of autonomy and justice may appear to be in conflict. In such an event, repeated communication and negotiating a middle path may be the best course. It would also be worth remembering that the physician is bound to act only according to professional standards of care and not obliged to follow blindly the dictates of the patient. ${ }^{[77]}$

\section{Conclusion and Future Directions}

The consensus document under the aegis of the ICMR has brought up to date, a glossary of terms relating to EOLC, limitation of life-sustaining treatment and palliative care. The definitions are based on accepted global standards in contemporary bioethical, medical, and legal literature. Currently, in India, the usage of the terms across professional, legal, and social domains has lacked standardization and clarity. This has proved to be a significant barrier to building consensus for public policy relating to EOLC, withdrawal and withholding of medical interventions, right to advance will, and euthanasia. This anomaly is expected to be corrected with this comprehensive position statement on the terms. This document is prepared to serve as an authoritative reference for dialog, research, and publications and to inform the ongoing formulation of a medicolegal framework for these areas.

\section{Benefits accrued}

1. The multi-professional consensus definitions lend themselves well to be understood by stakeholders across the several disciplines concerned with EOLC and palliative care

2. It brings clarity to outdated, inconsistent, and ambiguous terms used in EOLC and palliative care in India

3. It will serve to generate awareness of contemporary ethical and legal dimensions in medical care among both professionals and lay public

4. Based on standard methodology, it is an authoritative resource to inform legal opinion and public policy

5. Indian physicians seeking to practice as per international ethical guidelines will be better understood and protected as the definitions are rooted in contemporary bioethical concepts and principles

6. Indian patients will be benefitted by the universally accepted ethical principles finding expression in Indian medical practice.

\section{Acknowledgments}

We would like to acknowledge Soumya Swaminathan, DG ICMR and Secretary DHR, for commissioning an expert group to finalize definitions of terms pertaining to end-of-life care. We would also like to acknowledge Dr. Roli Mathur, Head, ICMR Bioethics Unit, for facilitating the process; Dr. Rajib Hazam and Dr. Kalyani Thakur for providing the secretarial support from ICMR. We would like to acknowledge other members of the commission who played a pivotal role in preparing this document: Anand Grover, Lawyers Collective, New Delhi; Dhvani Mehta, Vidhi Centre for Legal Policy, New Delhi; Nandini K Kumar, Formerly at ICMR, New Delhi; Nandini Vallath, Trivandrum Institute of Palliative Sciences, Thiruvananthapuram; Priyadarshini Kulkarni, Simpatico Palliative Connect, Pune; Sanjay Mehendale, ICMR, New Delhi; Sunita Bandewar, Independent Sr. Research Professional and Consultant, Pune; Tripti Tandon, Lawyers Collective, New Delhi; Vasantha Muthuswamy, Formerly at ICMR, New Delhi; Vijay Kumar, ICMR, New Delhi; Vimal Bhandari, National Organ and Tissue Transplant Organization, New Delhi.

\section{Financial support and sponsorship}

Nil. 


\section{Conflicts of interest}

There are no conflicts of interest.

\section{RefERENCES}

1. Ferrand E, Robert R, Ingrand P, Lemaire F; French LATAREA Group. Withholding and withdrawal of life support in Intensive-Care Units in France: A prospective survey. French LATAREA Group. Lancet 2001;357:9-14.

2. Sprung CL, Cohen SL, Sjokvist P, Baras M, Bulow HH, Hovilehto S, et al. End-of-life practices in European Intensive Care Units: The Ethicus study. JAMA 2003;290:790-7.

3. Kapadia F, Singh M, Divatia J, Vaidyanathan P, Udwadia FE, Raisinghaney SJ, et al. Limitation and withdrawal of intensive therapy at the end of life: Practices in Intensive Care Units in Mumbai, India. Crit Care Med 2005;33:1272-5.

4. Mani R. Limitation of life support in the ICU: Ethical issues relating to end of life care. Indian J Crit Care Med 2003;7:112.

5. Mani RK, Mandal AK, Bal S, Javeri Y, Kumar R, Nama DK, et al. End-of-life decisions in an Indian Intensive Care Unit. Intensive Care Med 2009;35:1713-9.

6. Macaden SC, Salins N, Muckaden M, Kulkarni P, Joad A, Nirabhawane V, et al. End of life care policy for the dying: Consensus position statement of Indian association of palliative care. Indian $\mathrm{J}$ Palliat Care 2014;20:171-81.

7. Mani RK. End-of-life care in India. Intensive Care Med 2006;32:1066-8.

8. Barnett VT, Aurora VK. Physician beliefs and practice regarding end-of-life care in India. Indian J Crit Care Med 2008;12:109-15.

9. Byock IR. The nature of suffering and the nature of opportunity at the end of life. Clin Geriatr Med 1996;12:237-52.

10. Gordon J. Medical humanities: To cure sometimes, to relieve often, to comfort always. Med J Aust 2005;182:5-8.

11. Cassel CK, Field MJ. Approaching Death: Improving Care at the End of Life. National Academies Press; 1997.

12. Bryce CL, Loewenstein G, Arnold RM, Schooler J, Wax RS, Angus DC, et al. Quality of death: Assessing the importance placed on end-of-life treatment in the Intensive-Care Unit. Med Care 2004;42:423-31.

13. Leung KK, Tsai JS, Cheng SY, Liu WJ, Chiu TY, Wu CH, et al. Can a good death and quality of life be achieved for patients with terminal cancer in a Palliative Care Unit? J Palliat Med 2010;13:1433-8.

14. Prendergast TJ, Claessens MT, Luce JM. A national survey of end-of-life care for critically ill patients. Am J Respir Crit Care Med 1998;158:1163-7.

15. Smith R. Principles of a good death. Br Med J 2000;320:129-30.

16. Steinhauser KE, Clipp EC, McNeilly M, Christakis NA, McIntyre LM, Tulsky JA, et al. In search of a good death: Observations of patients, families, and providers. Ann Intern Med 2000;132:825-32.

17. Chapman L, Ellershaw J. Care in the last hours and days of life. Medicine 2011;39:674-7.

18. Horton JN. Nominal group technique. A method of decision-making by committee. Anaesthesia 1980;35:811-4.

19. Okoli C, Pawlowski SD. The Delphi method as a research tool: An example, design considerations and applications. Inf Manage 2004; 42:15-29.

20. McCartney JJ, Trau JM. Cessation of the artificial delivery of food and fluids: Defining terminal illness and care. Death Stud 1990;14:435-44.

21. Hui D, Nooruddin Z, Didwaniya N, Dev R, De La Cruz M, Kim SH, et al. Concepts and definitions for "actively dying," "end of life," "terminally ill," "terminal care," and "transition of care": A systematic review. J Pain Symptom Manage 2014;47:77-89.

22. Jesus JE, Geiderman JM, Venkat A, Limehouse WE Jr., Derse AR, Larkin GL, et al. Physician orders for life-sustaining treatment and emergency medicine: Ethical considerations, legal issues, and emerging trends. Ann Emerg Med 2014;64:140-4.

23. Bosslet GT, Kesecioglu J, White DB. How should clinicians respond to requests for potentially inappropriate treatment? Intensive Care Med 2016;42:422-5.

24. Driscoll P. Cardio pulmonary resuscitation. J Accid Emerg Med 1994;11:56
25. Sidhu NS, Dunkley ME, Egan MJ. "Not-for-resuscitation" orders in Australian public hospitals: Policies, standardised order forms and patient information leaflets. Med J Aust 2007;186:72-5.

26. Lanken PN, Ahlheit BD, Crawford S, Hansen-Flaschen JH, Lefrak SS, Luce JM, et al. Withholding and withdrawing life-sustaining therapy. Am Rev Respir Dis 1991;144:726-31.

27. Materstvedt LJ, Clark D, Ellershaw J, Førde R, Gravgaard AM, Müller-Busch HC, et al. Euthanasia and physician-assisted suicide: A view from an EAPC ethics task force. Palliat Med 2003;17:97-101.

28. Snyder L, Sulmasy DP; Ethics and Human Rights Committee, American College of Physicians-American Society of Internal Medicine. Physician-assisted suicide. Ann Intern Med 2001;135:209-16.

29. WHO. Palliative care. WHO; 2007.

30. Sulmasy DP, Lynn J. End-of-life care. JAMA 1997;277:1854-5.

31. Cherny NI, Radbruch L; Board of the European Association for Palliative Care. European association for palliative care (EAPC) recommended framework for the use of sedation in palliative care. Palliat Med 2009;23:581-93.

32. de Graeff A, Dean M. Palliative sedation therapy in the last weeks of life: A literature review and recommendations for standards. J Palliat Med 2007;10:67-85.

33. McIntyre A. The double life of double effect. Theor Med Bioeth 2004;25:61-74.

34. Wijdicks EF. The diagnosis of brain death. N Engl J Med 2001;344:1215-21.

35. Cate FH. Human organ transplantation: The role of law. J Corp Law 1994;20:69.

36. Donnelly M. Best interests, patient participation and the mental capacity act 2005. Med Law Rev 2009;17:1-29.

37. Elwyn G, Edwards A, Kinnersley P, Grol R. Shared decision making and the concept of equipoise: The competences of involving patients in healthcare choices. Br J Gen Pract 2000;50:892-9.

38. Silveira MJ, Kim SY, Langa KM. Advance directives and outcomes of surrogate decision making before death. N Engl J Med 2010;362:1211-8.

39. Schwab AP. Formal and effective autonomy in healthcare. J Med Ethics 2006;32:575-9.

40. Pellegrino ED. For the Patient's Good: The Restoration of Beneficence in Health Care. 1988.

41. Gillon R. "Primum non nocere" and the principle of non-maleficence. Br Med J (Clin Res Ed) 1985;291:130-1.

42. Daniels N. Justice, health, and healthcare. Am J Bioeth 2001;1:2-16.

43. Peppercorn JM, Smith TJ, Helft PR, Debono DJ, Berry SR, Wollins DS, et al. American society of clinical oncology statement: Toward individualized care for patients with advanced cancer. J Clin Oncol 2011;29:755-60.

44. Cremer R, Hubert P, Grandbastien B, Moutel G, Leclerc F; GFRUP's Study Group on Forgoing Treatments. Prevalence of questioning regarding life-sustaining treatment and time utilisation by forgoing treatment in francophone PICUs. Intensive Care Med 2011;37:1648-55.

45. Bosslet GT, Pope TM, Rubenfeld GD, Lo B, Truog RD, Rushton CH, et al. An official ATS/AACN/ACCP/ESICM/SCCM policy statement: Responding to requests for potentially inappropriate treatments in Intensive Care Units. Am J Respir Crit Care Med 2015;191:1318-30.

46. Jacobs I, Nadkarni V, Bahr J, Berg RA, Billi JE, Bossaert L, et al. Cardiac arrest and cardiopulmonary resuscitation outcome reports: Update and simplification of the Utstein templates for resuscitation registries. A statement for healthcare professionals from a task force of the international liaison committee on resuscitation (American Heart Association, European Resuscitation Council, Australian Resuscitation Council, New Zealand Resuscitation Council, Heart and Stroke Foundation of Canada, InterAmerican Heart Foundation, Resuscitation Council of Southern Africa). Resuscitation 2004;63:233-49.

47. Cartwright $\mathrm{CM}$, Parker MH. Advance care planning and end of life decision making. Aust Fam Physician 2004;33:815-9.

48. Sprung CL, Truog RD, Curtis JR, Joynt GM, Baras M, Michalsen A, et al. Seeking worldwide professional consensus on the principles of end-of-life care for the critically ill. The consensus for worldwide end-of-life practice for patients in Intensive Care Units (WELPICUS) study. Am J Respir Crit Care Med 2014;190:855-66.

49. Downar J, Delaney JW, Hawryluck L, Kenny L. Guidelines for 
the withdrawal of life-sustaining measures. Intensive Care Med 2016;42:1003-17.

50. Ebrahimi N. The ethics of euthanasia. Aust Med Stud J 2012;3:73-5.

51. Weiss M. Illinois death with dignity act: A case for legislating physician assisted suicide and active euthanasia. Ann Health Law Adv Directive 2014;23:13-198.

52. Jinaru A. The practice of euthanasia - A criminal or compassionate act? Washington, USA: Knowledge and Action Within the Knowledge Based Society; 2012. p. 149.

53. Bosshard G, Nilstun T, Bilsen J, Norup M, Miccinesi G, van Delden JJ, et al. Forgoing treatment at the end of life in 6 European countries. Arch Intern Med 2005;165:401-7.

54. Slomka J. The negotiation of death: Clinical decision making at the end of life. Soc Sci Med 1992;35:251-9.

55. Ellershaw J, Ward C, Neuberger J. Care of the dying patient: The last hours or days of life/commentary: A" good death" is possible in the NHS. Br Med J 2003;326:30.

56. Mani RK. Coming together to care for the dying in India. Indian J Crit Care Med 2014;18:560-2.

57. Mani R, Amin P, Chawla R, Divatia J, Kapadia F, Khilnani P, et al. Limiting life-prolonging interventions and providing palliative care towards the end-of-life in Indian Intensive Care Units. Indian J Crit Care Med 2005;9:96.

58. Truog RD, Meyer EC, Burns JP. Toward interventions to improve end-of-life care in the pediatric Intensive Care Unit. Crit Care Med 2006;34:S373-9.

59. Cassell EJ, Rich BA. Intractable end-of-life suffering and the ethics of palliative sedation. Pain Med 2010;11:435-8.

60. Rousseau P. Existential Suffering and Palliative Sedation: A Brief Commentary With a Proposal for Clinical Guidelines. Thousand Oaks, CA: Sage Publications; 2001.

61. Simpson P, Bates D, Bonner S, Costeloe K, Doyal L, Falvey S, et al. A code of practice for the diagnosis and confirmation of death. London, United Kingdom: GB. Acadamy of Medical Royal Colleges; 2008.

62. Doyal L. The moral character of clinicians or the best interests of patients? BMJ 1999;318:1432-3.

63. Greaney N. Mental Capacity Act 2005: Law Society London; 2005.

64. Bartlett P. Blackstone's Guide to the Mental Capacity Act 2005; 2008.

65. Coulter A, Edwards A, Elwyn G, Thomson R. Implementing shared decision making in the UK. Z Evid Fortbild Qual Gesundhwes $2011 ; 105: 300-4$
66. Stiggelbout AM, Van der Weijden T, De Wit MP, Frosch D, Légaré F, Montori VM, et al. Shared decision making: Really putting patients at the centre of healthcare. BMJ 2012;344:e256.

67. Teno JM, Gruneir A, Schwartz Z, Nanda A, Wetle T. Association between advance directives and quality of end-of-life care: A national study. J Am Geriatr Soc 2007;55:189-94.

68. Closen ML, Maloney JE. The health care surrogate act in Illinois: Another rejection of domestic partners' rights. South Ill Univ Law J 1994;19:479.

69. Shroff S. Legal and ethical aspects of organ donation and transplantation. Indian J Urol 2009;25:348-55.

70. O'Neill RJ. Surrogate health care decisions for adults in Illinois-answers to the legal questions that health care providers face on a daily basis. Loyola Univ Chicago Law J 1997;29:411.

71. Truog RD, Campbell ML, Curtis JR, Haas CE, Luce JM, Rubenfeld GD, et al. Recommendations for end-of-life care in the Intensive Care Unit: A consensus statement by the American College [corrected] of Critical Care Medicine. Crit Care Med 2008;36:953-63.

72. Beauchamp TL, Childress JF. Principles of Biomedical Ethics. USA: Oxford University Press; 2001.

73. Crippen DW, Kilcullen JK, Kelly DF. Three Patients: International Perspective on Intensive Care at the End of Life. Kluwer Academic Publishers, London: Springer Science \& Business Media; 2002.

74. Cook D, Rocker G, Heyland D. Dying in the ICU: Strategies that may improve end-of-life care. Can J Anaesth 2004;51:266-72.

75. Medical Treatment of Terminally ill Patients (for the Protection of Patients and Medical Practitioners) $196^{\text {th }}$ Report of Law Commision of India; 2006. Available from: http://www.lawcommissionofindia.nic.in/ reports/rep196.pdf. [Last accessed on 2014 Aug 05].

76. Quill TE, Dresser R, Brock DW. The rule of double effect - A critique of its role in end-of-life decision making. N Engl J Med 1997;337:1768-71.

77. Thompson BT, Cox PN, Antonelli M, Carlet JM, Cassell J, Hill NS, et al. Challenges in end-of-life care in the ICU: Statement of the $5^{\text {th }}$ International Consensus Conference in Critical Care: Brussels, Belgium, April 2003: Executive summary. Crit Care Med 2004;32:1781-4

78. Hall RI, Rocker GM, Murray D. Simple changes can improve conduct of end-of-life care in the Intensive Care Unit. Can J Anaesth 2004;51:631-6.

79. ICMR. National Ethical Guidelines for Biomedical and Health Research Involving Human Participants. New Delhi: ICMR; 2017. 